\title{
Deconstructing Underlying Assumptions about Trafficked Minors and Children
}

\author{
Jeremy Norwood
}

Please cite this article as: J Norwood, 'Deconstructing Underlying Assumptions about Trafficked Minors and Children', Anti-Trafficking Review, issue 13, 2019, pp.120-124, https://doi.org/10.14197/atr.201219138

Review of: Trafficked Children and Youth in the United States: Reimagining Survivors, Elżbieta M. Goździak, Rutgers University Press, New Brunswick, 2016, 9780813569697.

In Trafficked Children and Youth in the United States: Reimagining Survivors, Elżbieta M. Goździak (2016) not only explores the experiences of children and youth who have been exploited by their traffickers, but she also addresses the system in the United States that seeks to intervene and assist them. In order to understand this apparent process of victimisation, Goździak articulates the need to deconstruct popular conceptions of human trafficking itself, particularly as she seeks to give voice to the survivors and lend credibility to the trauma that they have endured. In order to accomplish this larger purpose, Goździak begins by identifying service providers which assist in the aftercare process for those impacted by human trafficking. She then spends time visiting these aftercare facilities, listening to the children and youth survivors of human trafficking, and documenting their stories and life circumstances.

While Goździak focuses specifically on children and youth who mostly have been smuggled from their countries of origin into the United States and later trafficked, she also makes several major contributions which should be taken seriously by scholars and practitioners who work on the topic of human trafficking. Firstly, she demonstrates that human trafficking is very much a social phenomenon which is exacerbated by the structural ('push' and 'pull') factors at play between so-called 'origin' and 'destination' countries. Secondly, individuals often find themselves in positions where they have to take chances in order to better their circumstances, as well as those of their families. Finally, Goździak makes a significant contribution

This is an open-access article distributed under the terms of the Creative Commons Attribution License (CC-BY). Under the CC-BY license, the public is free to share, adapt, and make commercial use of the work. Users must always give proper attribution to the authors and the Anti-Trafficking Review. 
by interrogating many of the overarching myths that frame the captivity, rescue and rehabilitation of trafficked children and youth. What is especially powerful about this final contribution is that she debunks the popular myths surrounding human trafficking by using quantitative and qualitative data to reshape commonly held perceptions about the issues. This review will seek to elaborate on these scholarly contributions to the field of human trafficking by dissecting the larger points made by Goździak throughout the text.

One of the first contributions to the existing critical scholarship on human trafficking embodied in Goździak's work is the understanding of structural factors at play in the process of trafficking itself. First and foremost, the author uses a critical lens to highlight a range of contested ideological perspectives on human trafficking. In order to do this, she first deconstructs the popular, widely utilised framework through which some academics and practitioners view the process of 'captivity, rescue, and rehabilitation' (p. 17). According to Goździak, the moral and political agenda often shapes the research on human trafficking, leading to distorted statistics on its nature and prevalence, which have been contrived without rigorous research methodologies (pp. 31-32). She uses examples of how such statistics abound, despite the lack of particular methodologies in assembling them. This agenda often incorporates a rather paternalistic viewpoint, which conveniently places those who have been trafficked into a set of categories to be studied and analysed, and views them as helpless individuals to be 'saved' or 'rescued' instead of acknowledging the complexities of individual circumstances that do not fit easily into prescribed binaries (p. 32). For example, how do we reconcile the definition of a 'child' as anyone below the age of 18 , when in some socio-economic contexts, children take on 'adult' responsibilities earlier in life than they might in the United States? How do we situate various understandings of 'adulthood' within a global context (pp. 113-117)?

As part of this process, Goździak also seeks to place trafficked persons within a larger web of social structures. These include, but are not limited to, how those who are exploited are situated in an economic, educational, political and social context. In other words, she utilises the literature on migration in order to provide more context to the situations individuals find themselves in based on 'push' and 'pull' factors, which transcend their day-to-day choices. This informed discourse is particularly important in some political and cultural contexts where labels are used to dehumanise individuals into roles as if these terms fully embodied their humanity and identity. For example, using terms such as 'illegal' or 'prostitute' often perpetuates this process of dehumanisation. In fact, such labelling nomenclature not only serves to minimise the structural impetus for the social phenomenon of human trafficking, but it also dispels any supposed agency exercised by trafficked people. As Goździak articulates, it is imperative to understand the structures which shape our understanding of reality, particularly in the case of those who have been trafficked. 
A second major contribution Goździak makes involves her ability to portray 'the coexistence of agency and vulnerability, the interplay of trauma and resiliency of survivors of human trafficking' (p. 5). While the moral and political bias is inherent in much of the quantitative data on human trafficking, the data Goździak collected through the stories of trafficked children and youth reveal a deep sense of connection between the survivors and the individuals responsible for their captivity and exploitation. This level of agency is at times overshadowed by the supposed vulnerability of those who are being trafficked, particularly if they are children. Those de jure 'perpetrators', according to Goździak, did not fit the common perceptions moulded by the popular representations of trafficking, the majority of which focus on the vulnerability of the supposed victims to the detriment of any level of relationship between the parties involved. In fact, while there are undoubtedly organised criminal elements which engage in child trafficking, an overwhelming number of cases unearthed by Goździak involved people close to the survivors such as mothers, fathers, uncles, siblings, other close family members, and intimate partners or spouses (pp. 55-57). Furthermore, many of these family members and/or relatives had initially sought to assist the survivors, who often found themselves unknowingly constrained by the structural 'push' factors of their respective countries of origin, in order to attain a better standard of living in the United States (one of the 'pull' factors). As the author describes the complex dynamics of the process of human trafficking beyond the 'trafficker/trafficked' oversimplification, it is much easier to conceptualise the various stages at which survivors have been 'recruited, harbored, transported, provided for, obtained, solicited, or patronized' (Trafficking Victims Protection Act, 2000).

The paradigm shift, however, comes in as these survivors have sought assistance from those they know and sometimes love as part of this process. In order to encourage the reader to fully grasp the enormity of this paradigm shift, Goździak asks some fairly compelling questions: What happens when members or acquaintances of traditional or nuclear families have taken part in this process only to find out later that the individuals they were trying to help have been trafficked? Does that make the well-intentioned family members complicit in the crime of human trafficking? What if one of these well-intentioned family members is complicit in either smuggling or trafficking? What if the survivors do not want to disclose details which would help investigations because of a duty to provide for their families in lieu of observing their own rights—a knowing renunciation of expressing voice or agency? (pp. 66-67). This level of connection amongst survivors and those who have played a role in helping them secure a more stable standard of living presents some compelling legal challenges to identifying trafficked persons in the United States. This level of connection can also, as Goździak points out, pit these survivors against those who have raised them and supported their passage to the US, and limit their prospects of employment indefinitely (pp. 66-67). As a result, this connection may shape the level of 'captivity' survivors find themselves in, as well as severely hamper the success of 
'rescuing' them, and cause friction when discussing the best action plan in terms of recovery.

In addition to establishing the confluence of terms such as agency and vulnerability, and trauma and resiliency, a final contribution that Goździak makes is her attention to many myths, which inform our current understanding of human trafficking. While many of these myths result from an incomplete (and sometimes ignorant) understanding of the phenomenon, Goździak suggests that they often help shape various levels of intervention. In particular, she provides data to debunk the myth that individuals are often found chained or bound in their places of captivity. While this is true in a minority of cases, this imagery continues to embody certain aspects of the anti-trafficking rhetoric through several decals, graphics, and advertisements by well-meaning anti-trafficking actors, including NGOs and governments. Per the discussion on agency, the majority of survivors were unbound, willing participants in the initial stages of what later turned out to be, in many cases, human trafficking. This realisation profoundly shapes our understanding of survivors, who desperately seek 'to rebuild their lives by securing good jobs, being able to send remittances home, learning English, developing friendships, and finding love' (p. 5).

The author also addresses the question of what happens when trafficked persons are the ones who are charged for crimes committed during the human trafficking situation. If trafficked persons are charged with a crime related to the trafficking situation, they begin to mistrust the authorities. It should come as no surprise, as Goździak points out, that one of the first steps in making a recognisable dent in the fight against human trafficking is to focus on those who are profiting from trafficking instead of re-victimising those who are being continuously exploited (pp. 98-99). These power dynamics shed light on the structural causes of human trafficking, which are often driven by demand for cheap and exploitable domestic, sexual and other services and labour. This also serves to take the focus off of the stigmatisation and labelling, which take place with marginalised and exploitable populations who are most vulnerable to being trafficked. In other words, if the causes of human trafficking are more clearly understood, there is less of an onus of responsibility placed on the victims.

I found this book remarkable in terms of questioning many of the commonly held assumptions about human trafficking. While it may be more convenient to assemble a study on human trafficking which provides a decent bird's eye view from the treetops, Goździak's book instead begins with grassroots research, which consciously lends voice to the survivors in order to understand not what human trafficking 'looks like', but instead what it actually is through personal interactions and conversations. In doing so, the author was able to deconstruct many of the assumptions regarding human trafficking circulated by some professionals in order to better inform those working with survivors as well as policymakers. All in all, 
Goździak's project successfully recaptures the scholarship on human trafficking, some of which currently embodies the presumptuous tones of moral and political elitism, and returns it to the survivors by telling their stories and allowing them to speak their minds about what types of 'captivity' they are most familiar with, the types of intervention that are most needed, and the recovery that would best serve their interests.

Dr Jeremy Norwood, J.D., is currently a Professor of Sociology, Global Studies, and Criminal Justice at Spring Arbor University in Spring Arbor, Michigan. His primary research interests focus on how human trafficking intersects with migration, international development and law. Over the past several years, he has provided over fifty trainings and workshops on human trafficking, primarily for professionals in the areas of counselling, social work and dental hygiene, but also for churches and other community groups. His current book project focuses on the issue of human trafficking within the State of Michigan. Email: Jeremy. Norwood@arbor.edu 